\title{
ESPECIFICAÇÃO DE UM SISTEMA COMPUTACIONAL INTEGRADO DE CONTROLE DE INCÊNDIOS FLORESTAIS
}

\author{
José Renato Soares Nunes*, Ronaldo Viana Soares**, Antônio Carlos Batista*** \\ *Eng. Florestal, Dr., Pós-Doutorando em Engenharia Florestal, UFPR - zerenato06@yahoo.com.br \\ **Eng. Florestal, Ph.D., Depto. de Ciências Florestais, UFPR - rvsoares@ufpr.br \\ ***Eng. Florestal, Dr., Depto. de Ciências Florestais, UFPR - batistaufpr@fufpr.br \\ Recebido para publicação: 03/02/2006 - Aceito para publicação: 16/06/2006
}

\begin{abstract}
Resumo
O objetivo deste trabalho é especificar um sistema computacional, utilizando a modelagem funcional, que permita calcular o índice de perigo de incêndios florestais pela Fórmula de Monte Alegre (FMA) e Fórmula de Monte Alegre Alterada $\left(\mathrm{FMA}^{+}\right)$e armazenar informações referentes aos incêndios florestais, permitindo também a geração de estatísticas sobre índices de perigo e ocorrência de incêndios florestais. Após a análise do problema, foram criados o Diagrama de Contexto, os Diagramas de Fluxo de Dados de Nível 1 e de Nível 2 e o Diagrama de Entidade-Relacionamento, de acordo com as técnicas de modelagem funcional e modelagem de dados. Foram definidas as funcionalidades de todos os processos que irão compor o futuro Sistema Integrado de Controle de Incêndios Florestais. Na especificação do Modelo Conceitual, foi feita a descrição do banco de dados de maneira independente do Sistema de Gerenciamento de Banco de Dados (SGBD), permitindo que ele seja implementado em qualquer tipo de SGBD. Na especificação do Modelo Lógico, foi feita a descrição do banco de dados considerando a adoção de um Sistema de Gerenciamento de Banco de Dados Relacional.

Palavras-chave: Sistema de incêndios florestais; banco de dados de incêndios florestais; proteção florestal.
\end{abstract}

\begin{abstract}
Specification of an integrated wildfire control computational system. The main objectives of this paper were to specify a computational system, using the functional modeling, that allows to calculate the forest fire danger index through the Monte Alegre Formula - FMA and the Modified Monte Alegre Formula - $\mathrm{FMA}^{+}$and to store information of forest fire occurrence, allowing the generation of danger indices and forest fire occurrence statistics. From the analysis of the problem, the Context Diagram, the Level 1 and Level 2 Data-Flow Diagrams, and the Entity-Relationship Diagram were created, in accordance with the techniques of functional modeling. The process functionalities that will compose the future Integrated Forest Fire Control System was also defined. In the specification of the Conceptual Model the description of the data base in independent way of the Data Base Management System - DBMS was carried out. This abstraction in relation to the DBMS allows its implementation in any type of DBMS. In the specification of the Logical Model the description of the data base considering the adoption of a Relational Data Base Management System was made.

Keywords: Wildfire prevention system; wildfire data base; forest protection.
\end{abstract}

\section{INTRODUÇÃO}

Os incêndios florestais no Brasil tornam-se a cada ano mais críticos, com o aumento da extensão da área queimada e os conseqüentes danos ao ambiente e à produção florestal. A falta de um programa institucional consistente é um dos grandes problemas que contribuem para que esse cenário se agrave, apesar do aperfeiçoamento das técnicas de controle de incêndios florestais disponíveis. A melhoria das técnicas de prevenção e combate não pode ser conseguida pela simples adoção de tecnologias que outros países já desenvolveram, mas sim através de programas que visem aprimorar e aproveitar as experiências existentes, desenvolvendo-se novas tecnologias, com a devida adequação à realidade brasileira.

A ocorrência e propagação dos incêndios florestais estão fortemente associadas às condições 
climáticas ou fatores climáticos. A intensidade de um incêndio e a velocidade com que ele avança estão diretamente ligados à umidade relativa, temperatura do ar e velocidade do vento (CHENEY, 1968; SCHROEDER e BUCK, 1970; HEIKKILÄ et al. 1993). A utilização de informações meteorológicas e climatológicas precisas é, portanto, vital para o planejamento de prevenção e combate aos incêndios florestais (SOARES, 1984; BATISTA, 1990).

Apesar do grande avanço das técnicas de combate a incêndios florestais existentes atualmente, as técnicas de prevenção não apresentaram o mesmo ritmo de evolução. Vale ressaltar que, dentre as medidas preventivas existentes, a utilização de um índice de perigo confiável é fator fundamental para um planejamento mais eficiente das medidas de prevenção e para a adoção de ações rápidas e efetivas nas atividades de combate aos incêndios florestais, visando a redução das perdas e, conseqüentemente, dos prejuízos financeiros advindos da ocorrência de eventos catastróficos.

No Brasil, a falta de informações integradas em âmbito nacional ou mesmo regional é um dos sérios problemas para os técnicos que atuam na prevenção e combate aos incêndios florestais, razão pela qual está sendo apresentada esta proposta de trabalho.

O objetivo deste trabalho é especificar um sistema computacional, utilizando a modelagem funcional e a modelagem de dados, visando calcular e armazenar o índice de perigo de incêndios florestais pela Fórmula de Monte Alegre - FMA (SOARES, 1972a; SOARES, 1972b) e Fórmula de Monte Alegre Alterada - $\mathrm{FMA}^{+}$(NUNES, 2005), bem como informações referentes aos incêndios florestais, permitindo a geração de estatísticas sobre os índices de perigo e a ocorrência desse tipo de incêndios. Outras funcionalidades foram incorporadas na especificação, como a correção da umidade relativa, o cálculo da umidade relativa a partir das temperaturas obtidas de um psicrômetro e uma medida da eficiência dos índices de perigo adotados.

\section{MATERIAL E MÉTODOS}

\section{Modelagem Funcional}

Segundo Yourdon (1992) e Pompilho (1995), a modelagem funcional se baseia na representação em forma gráfica da interdependência das funções que compõem um sistema. Alguns elementos gráficos são utilizados para caracterizar os processos e os dados manipulados pelos processos.

\section{Diagrama de Contexto}

O primeiro nível de detalhamento é representado pelo Diagrama de Contexto, que dá uma idéia geral do sistema e de seu relacionamento com entidades externas a ele.

\section{Diagrama de Fluxo de Dados Nível 1}

O segundo nível de detalhamento é representado pelos Diagramas de Fluxo de Dados de Nível 1, que apresenta uma visão geral dos principais processos que irão compor o sistema.

\section{Diagrama de Fluxo de Dados Nível 2}

O terceiro nível de detalhamento é representado pelos Diagramas de Fluxo de Dados de Nível 2, que apresenta de forma detalhada os processos que irão compor o sistema.

Após a análise do problema, foram criados o Diagrama de Contexto e os Diagramas de Fluxo de Dados de Nível 1 e de Nível 2, de acordo com as técnicas de modelagem funcional (YOURDON, 1992; GANE e SARSON, 1995; POMPILHO, 1995).

Foram também definidas as funções de todos os processos que irão compor o futuro Sistema Integrado de Incêndios Florestais.

\section{Modelagem de Dados}

A maioria dos bancos de dados existentes segue um modelo conhecido por modelo relacional, que se caracteriza por uma coleção de tabelas, cada qual designada por um nome único. Uma tupla numa tabela representa um relacionamento entre um conjunto de valores. Como uma tabela é uma coleção de relacionamentos, existe uma correspondência entre o conceito de tabela e o conceito matemático de relação. Por essa correspondência entre tabela e relação, originou-se o nome "modelo relacional" (SILBERSCHATZ et al. 1999; DATE, 2000). 
O estudo do modelo de dados relacional apresenta 3 aspectos:

- Aspectos estruturais: formalizam matematicamente a maneira como os dados estão organizados no modelo. Essa formalização é baseada na teoria dos conjuntos.

- Aspectos de integridade: descrevem os procedimentos para garantir a integridade de dados quando da ocorrência de operações de atualização de dados.

- Aspectos de manipulação: descrevem as linguagens formais e comerciais definidas para o modelo.

A estrutura do modelo relacional baseia-se em 5 conceitos: domínio, que é o conjunto de valores permitidos para um dado; atributo, que é um item de dado do banco de dados; tupla, que é um conjunto de pares (atributo, valor); relação, que é um conceito matemático que explica o relacionamento entre um conjunto de valores; e chave, que é o conjunto de um ou mais atributos de uma relação.

\section{Projeto de banco de dados}

Todo sistema de banco de dados deve apresentar um projeto, que visa a organização das informações e utilização de técnicas para que o futuro sistema obtenha bom desempenho e também facilite as manutenções necessárias.

O projeto de banco de dados se dá em duas fases:

a) Modelagem conceitual;

b) Projeto lógico.

\section{Modelo Conceitual}

Na especificação do Modelo Conceitual, foi feita a descrição do banco de dados de maneira independente do Sistema de Gerenciamento de Banco de Dados (SGBD), ou seja, foram definidos quais os dados que aparecerão no banco de dados, mas sem se importar com a implementação. Dessa forma, há uma abstração em relação ao SGBD, permitindo que ele seja implementado em qualquer tipo de SGBD.

Uma das técnicas mais utilizadas para representar o Modelo Conceitual é a abordagem EntidadeRelacionamento, em que o modelo é representado graficamente através do Diagrama EntidadeRelacionamento (DER), técnica que foi utilizada neste trabalho.

\section{Modelo Lógico}

$\mathrm{Na}$ especificação do Modelo Lógico, foi feita a descrição do banco de dados considerando a adoção de um Sistema de Gerenciamento de Banco de Dados Relacional. O Modelo Lógico depende do tipo particular de SGBD que será usado. Não se deve confundir com o software que será usado. O tipo de SGBD de que o Modelo Lógico trata se refere à estrutura a ser utilizada e pode ser relacional, orientado a objetos ou hierárquico.

O modelo de banco de dados relacional adotado neste trabalho exige a definição das tabelas e o nome das colunas que irão compor essas tabelas.

\section{RESULTADOS E DISCUSSÃO}

A partir das análises da estrutura dos dados de entrada, das informações a serem geradas e da funcionalidade desejada, pode-se definir a estrutura do sistema, composto dos módulos apresentados a seguir.

\section{Especificação do Diagrama de Contexto}

Como apresentado no Diagrama de Contexto (Figura 1), o Sistema Integrado de Incêndios Florestais deve ser capaz de receber dados meteorológicos e dados sobre a ocorrência de incêndios florestais e produzir informações sobre o perigo de incêndios, estatísticas dos incêndios e comportamento do fogo, auxiliando na tomada de decisões sobre o controle de tais incêndios.

\section{Especificação do Diagrama de Fluxo de Dados Nível 1}

Em um primeiro nível de detalhamento, o Sistema Integrado de Incêndios Florestais foi dividido em dois processos distintos, como apresentado na figura 2: o processo Determinação de Índices de Perigo de Incêndios Florestais e o processo de Atualização da Base de Incêndios Florestais. 


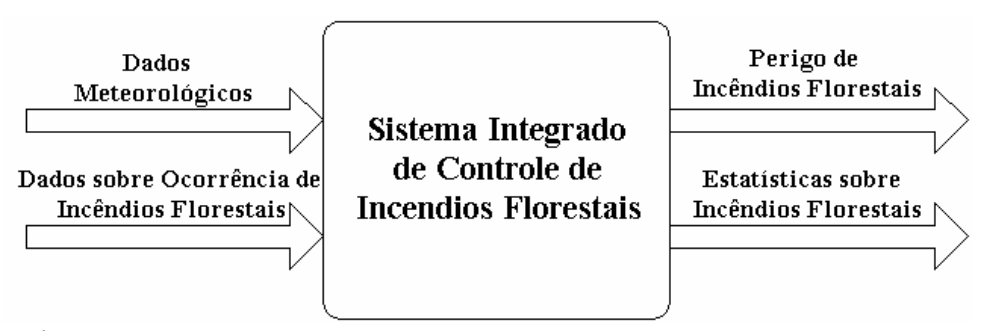

Figura 1. Diagrama de contexto.

Figure 1. Context diagram.

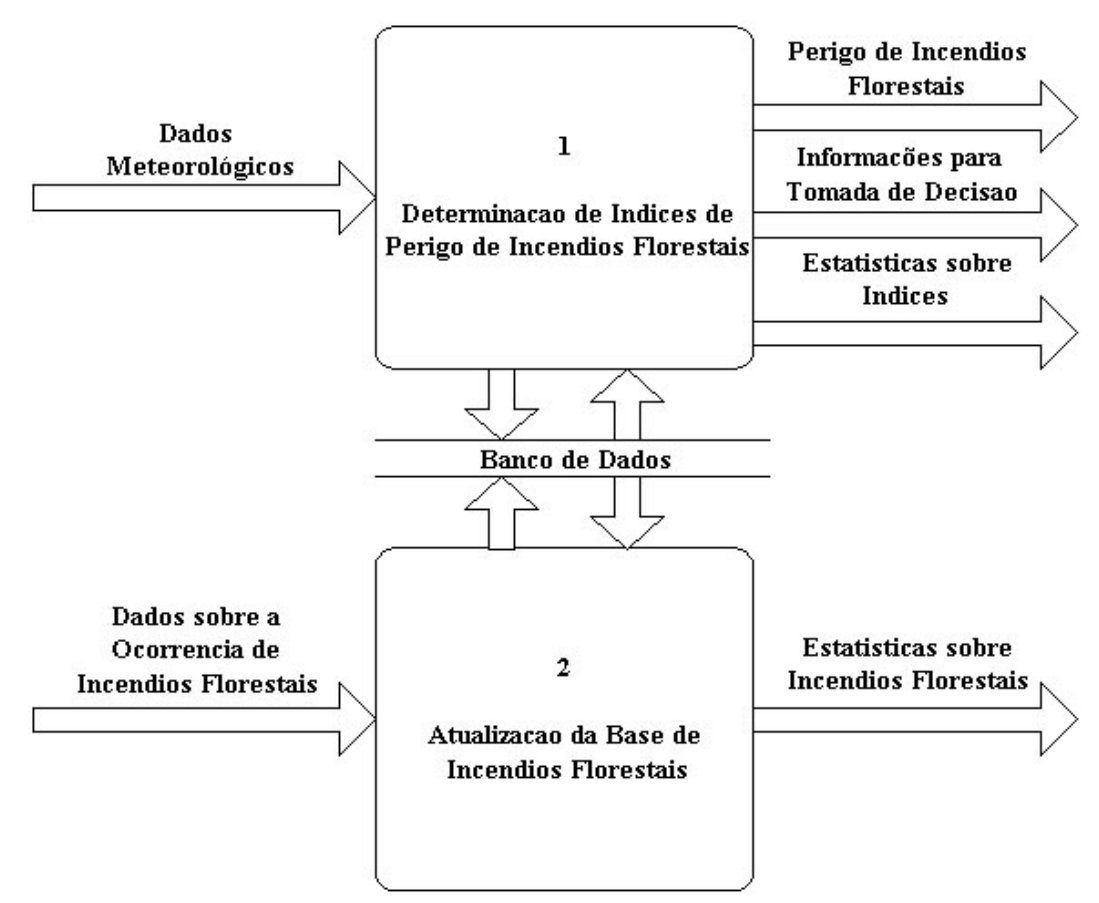

Figura 2. Diagrama de fluxo de dados nível 1.

Figure 2. Level 1 data-flow diagram.

\section{Especificação do Diagrama de Fluxo de Dados Nível 2}

As figuras 3 e 4 apresentam, respectivamente, o detalhamento dos processos de Determinação de Índices de Perigo de Incêndios Florestais e Atualização da Base de Incêndios Florestais. Cada um dos processos apresentados, identificados por 1.1, 1.2, 1.3, 1.4, 1.5, 1.6, 1.7, 1.8, 1.9, 2.1, 2.2, 2.3, será descrito a seguir.

\section{Descrição dos processos}

1.1 Comportamento do sistema - Permite ao usuário optar entre as duas principais funções do sistema: determinação de índices de perigo de incêndios florestais ou atualização da base de incêndios florestais. Permite ainda ao usuário escolher entre a Fórmula de Monte Alegre (FMA) e a Fórmula de Monte Alegre Alterada $\left(\mathrm{FMA}^{+}\right)$.

1.2 Entrada de dados - Permite ao usuário escolher como será feita a entrada de dados meteorológicos, podendo ser manual ou através da importação de arquivos em um determinado formato.

1.3 Calcula a umidade relativa - Módulo interno que, a partir das temperaturas dos bulbos úmido e seco do psicrômetro e da altitude, calcula a umidade relativa.

1.4 Corrige umidade relativa - Módulo interno, acionado quando o usuário coleta a umidade relativa às 9:00 ou 15:00 horas, pois a mesma deve ser corrigida para as 13:00 horas. 
1.5 Calcula FMA - Módulo interno, acionado por opção do usuário quando não possui dados de velocidade do vento das 13:00 horas ou só possui dados de velocidade do vento das 9:00 ou 15:00 horas, uma vez que a velocidade do vento não será corrigida.

1.6 Calcula $\mathrm{FMA}^{+}$- Módulo interno, acionado por opção do usuário. Nesse caso, deve-se ter os dados de velocidade do vento das 13:00 horas.

1.7 Determina grau de perigo - Módulo interno que apresenta ao usuário o grau de perigo para o dia a partir dos dados lançados.

1.8 Gera informações para tomada decisão - Módulo interno que apresenta as medidas preventivas associadas a cada grau de perigo de FMA e $\mathrm{FMA}^{+}$.

1.9 Gera estatísticas - Permite ao usuário obter estatísticas referentes aos índices de perigo FMA e $\mathrm{FMA}^{+}$, como o número e o percentual de dias em cada classe de perigo previstos em um determinado período, apresentando o resultado de forma textual e gráfica.

2.1 Entrada de dados - Permite ao usuário escolher como será feita a entrada de dados referente à ocorrência de incêndios, podendo ser manual ou através da importação de arquivos em um determinado formato.

2.2 Atualiza dados - Permite ao usuário realizar a atualização da base de dados, modificando e excluindo dados.

2.3 Gera outras estatísticas - Permite ao usuário obter estatísticas referentes à ocorrência de incêndios florestais, tais como o número e o percentual de incêndios registrados em cada classe de perigo, a área queimada e o percentual em cada classe de perigo e a área queimada média por incêndio em cada classe de perigo em um determinado período, apresentando o resultado de forma textual e gráfica. Permite ao usuário obter o skill score e a porcentagem de sucesso, confrontando os valores previstos com os ocorridos, o que dá uma medida da adequação do modelo à região onde está sendo usado.

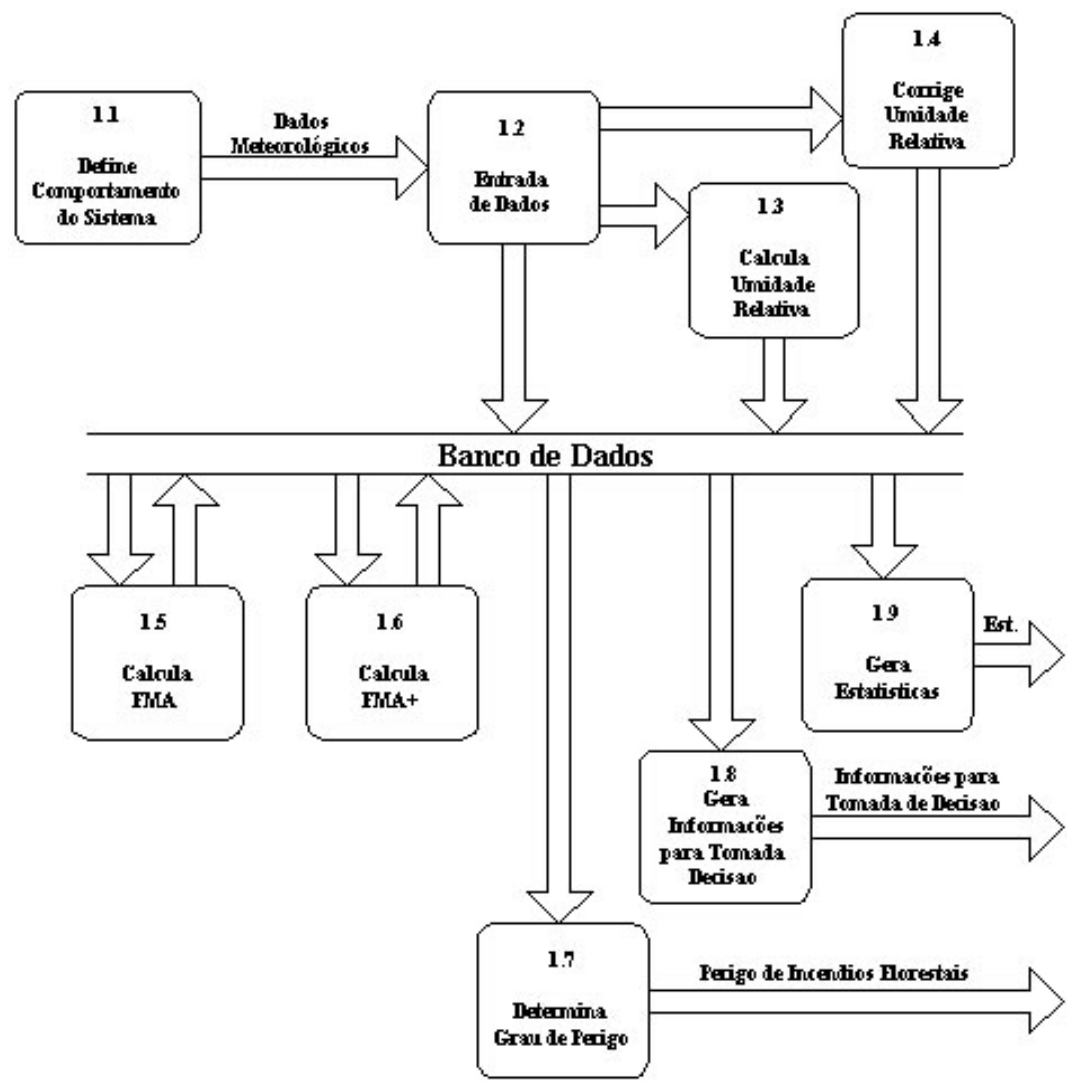

Figura 3. Diagrama de fluxo de dados nível 2: determinação de índices de perigo de incêndios florestais. Figure 3. Level 2 data-flow diagram:fire danger index determination. 


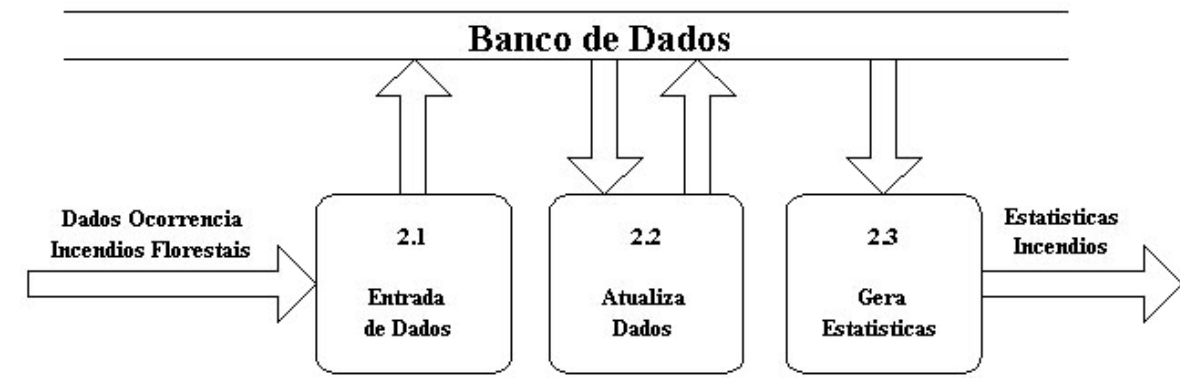

Figura 4. Diagrama de fluxo de dados nível 2: atualização da base de incêndios florestais.

Figure 4. Level 2 data-flow diagram: wildfire database update.

\section{Base teórica para os principais algoritmos}

Cálculo da umidade relativa

Para o cálculo da umidade relativa a partir das temperaturas dos bulbos úmido e seco do psicrômetro e da altitude, foram utilizadas as seguintes fórmulas (SOARES; BATISTA, 2004):

a) Cálculo da pressão atmosférica:

$$
\mathrm{P}_{\mathrm{z}}=760(1-0,0065 \mathrm{z} / 288)^{5,2568}
$$

Sendo: $\mathrm{P}_{\mathrm{z}}=$ pressão atmosférica em uma dada altitude em $\mathrm{mmHg}$; $\mathrm{z}=$ altitude em metros.

b) Determinação da pressão máxima de vapor d'água:

$$
\mathrm{E}_{\mathrm{T}}=4,58 \times 10^{(7,5 \mathrm{~T} / 237,3+\mathrm{T})}
$$

Sendo: $\mathrm{E}_{\mathrm{T}}=$ pressão máxima de vapor d'água na temperatura $\mathrm{T}$, em $\mathrm{mmHg}$; $\mathrm{T}=$ temperatura do ar em ${ }^{\circ} \mathrm{C}$.

c) Determinação da pressão máxima de vapor para a temperatura do bulbo úmido, em mmHg:

$$
\mathrm{E}^{\prime}=4,58 \times 10^{\left(7,5 \mathrm{~T}^{\prime} / 237,3+\mathrm{T}^{\prime}\right)}
$$

Sendo: $\quad E^{\prime}$ = pressão máxima de vapor d'água na temperatura T' (bulbo úmido), em mmHg; $\mathrm{T}^{\prime}=$ temperatura do bulbo úmido em ${ }^{\circ} \mathrm{C}$.

d) Determinação da pressão real de vapor:

$$
\mathrm{e}=\mathrm{E}^{\prime}-\mathrm{C} \mathrm{P}_{\mathrm{z}}\left(\mathrm{T}-\mathrm{T}^{\prime}\right)
$$

Sendo: $\mathrm{e}=$ pressão real de vapor, em $\mathrm{mmHg}$;

E' = pressão máxima de vapor d'água para a temperatura T';

$\mathrm{C}=$ constante psicrométrica: $\mathrm{C}=0,0008$ sem ventilação forçada; $\mathrm{C}=0,0006$ com ventilação;

$\mathrm{P}_{\mathrm{z}}=$ pressão atmosférica em $\mathrm{mmHg}$;

$\mathrm{T}=$ temperatura do ar (bulbo seco) em ${ }^{\circ} \mathrm{C}$;

$\mathrm{T}^{\prime}$ = temperatura do bulbo úmido em ${ }^{\circ} \mathrm{C}$.

e) Determinação da Umidade Relativa:

$$
\mathrm{UR}=\left(\mathrm{e} / \mathrm{E}_{\mathrm{T}}\right) \cdot 100
$$

\section{Correção da umidade relativa}

Segundo Nunes (2005), a estimativa da umidade relativa diária das 13:00 h, válida para o estado do Paraná, pode ser obtida através da leitura da umidade relativa das 9:00 h, mediante a equação:

$$
\mathrm{UR}_{13}=\mathrm{e}^{(2.72976+0.162192 \mathrm{UR}} 09^{)}
$$


A estimativa da umidade relativa diária das 13:00 h, válida para o estado do Paraná, pode ser obtida através da leitura da umidade relativa das 15:00 h, mediante a equação:

$$
\mathrm{UR}_{13}=2.451510 \mathrm{UR}_{15}^{0.79672}
$$

Cálculo da FMA

A equação básica da Fórmula de Monte Alegre é a seguinte (SOARES, 1972b):

$$
\mathrm{FMA}=\underset{\mathrm{i}=1}{\mathrm{n}}(100 / \mathrm{H})
$$

Sendo: $\quad$ FMA = Fórmula de Monte Alegre;

$\mathrm{H}=$ umidade relativa do ar $(\%)$, medida às 13:00 $\mathrm{h}$;

$\mathrm{n}=$ número de dias sem chuva maior ou igual a $13,0 \mathrm{~mm}$.

Por ser acumulativo, o índice está sujeito às restrições de precipitação, como mostra a tabela 1.

Tabela 1. Restrições da Fórmula de Monte Alegre em função da quantidade de chuva do dia.

Table 1. Restrictions to the daily FMA summation according to the precipitation.

\begin{tabular}{ll}
\hline Chuva do dia (mm) & \multicolumn{1}{c}{ Modificação no cálculo } \\
\hline$\leq 2,4$ & Nenhuma \\
2,5 a 4,9 & Abater $30 \%$ na FMA calculada na véspera e somar $(100 / \mathrm{H})$ do dia. \\
5,0 a 9,9 & Abater $60 \%$ na FMA calculada na véspera e somar $(100 / \mathrm{H})$ do dia. \\
10,0 a 12,9 & Abater $80 \%$ na FMA calculada na véspera e somar $(100 / \mathrm{H})$ do dia. \\
$>12,9$ & Interromper o cálculo $(\mathrm{FMA}=0)$ e recomeçar o somatório no dia seguinte ou quando a \\
& precipitação for menor ou igual a $2,4$. \\
\hline
\end{tabular}

A interpretação do grau de perigo estimado pela Fórmula de Monte Alegre é feita por meio da escala apresentada na tabela 2 .

Tabela 2. Escala de perigo da Fórmula de Monte Alegre.

Table 2. Forest fire danger scale for the FMA.

\begin{tabular}{lc}
\hline Valor de FMA & Grau de Perigo \\
\hline$\leq 1,0$ & Nulo \\
1,1 a 3,0 & Pequeno \\
3,1 a 8,0 & Médio \\
8,1 a 20,0 & Alto \\
$>20,0$ & Muito alto \\
\hline
\end{tabular}

\section{Cálculo de $\mathrm{FMA}^{+}$}

A Fórmula de Monte Alegre Alterada $-\mathrm{FMA}^{+}$(NUNES, 2005), que inclui a velocidade do vento, tem a seguinte representação:

$$
\mathrm{FMA}^{+}=\sum_{\mathrm{i}=1}^{\mathrm{n}}\left(100 / \mathrm{H}_{\mathrm{i}}\right) \mathrm{e}^{0,04 \mathrm{v}}
$$

Sendo: $\mathrm{FMA}^{+}=$Fórmula de Monte Alegre Alterada;

$\mathrm{H}=$ umidade relativa do ar em porcentagem, medida às 13:00 h;

$\mathrm{n}=$ número de dias sem chuva maior ou igual a $13,0 \mathrm{~mm}$;

$\mathrm{v}=$ velocidade do vento em $\mathrm{m} / \mathrm{s}$, medida às 13:00h;

$\mathrm{e}=$ base dos logaritmos naturais $(2,718282)$.

Por ser acumulativo, o índice está sujeito às mesmas restrições de precipitação apresentadas na tabela 1. A interpretação do grau de perigo estimado pela $\mathrm{FMA}^{+}$é feita através da escala apresentada na tabela 3 . 
Tabela 3. Escala de perigo da FMA+.

Table 3. Forest fire danger scale for the FMA+.

\begin{tabular}{lc}
\hline Valor de FMA $^{+}$ & Grau de Perigo \\
\hline$\leq 3,0$ & Nulo \\
3,1 a 8,0 & Pequeno \\
8,1 a 14,0 & Médio \\
14,1 a 24,0 & Alto \\
$>24,0$ & Muito alto \\
\hline
\end{tabular}

\section{Determinação do skill score e porcentagem de sucesso}

Para comparar os modelos, foi utilizado o método conhecido como skill score (SAMPAIO, 1999), que se baseia em uma tabela de contingência que contém os valores observados e os valores previstos para um evento em uma população. As tabelas 4 e 5 ilustram como são realizados os cálculos para se obter o skill score.

Tabela 4. Tabela de contingência.

Table 4. Contingency table.

\begin{tabular}{llccc}
\hline \multirow{2}{*}{ Evento } & & \multicolumn{2}{c}{ Observado } & \multirow{2}{*}{ Total previsto } \\
\cline { 3 - 4 } & & Incêndio & Não incêndio & \\
\hline Previsto & Incêndio & $\mathrm{a}$ & $\mathrm{b}$ & $\mathrm{N} 2=\mathrm{a}+\mathrm{b}$ \\
& Não incêndio & $\mathrm{c}$ & $\mathrm{d}$ & $\mathrm{N} 4=\mathrm{c}+\mathrm{d}$ \\
\hline Total observado & & $\mathrm{N} 1=\mathrm{a}+\mathrm{c}$ & $\mathrm{N} 3=\mathrm{b}+\mathrm{d}$ & $\mathrm{N}=\mathrm{a}+\mathrm{b}+\mathrm{c}+\mathrm{d}$ \\
\hline
\end{tabular}

Tabela 5. Cálculos da tabela de contingência.

Table 5. Contingency table calculations.

\begin{tabular}{llccc}
\hline \multirow{2}{*}{ Evento } & & \multicolumn{2}{c}{ Observado } & \multirow{2}{*}{ Total previsto } \\
\cline { 3 - 4 } & & Incêndio & Não incêndio & \\
\hline Previsto & Incêndio & $\mathrm{a} /(\mathrm{a}+\mathrm{c})$ & $\mathrm{b} /(\mathrm{b}+\mathrm{d})$ & 1 \\
& Não incêndio & $\mathrm{c} /(\mathrm{a}+\mathrm{c})$ & $\mathrm{d} /(\mathrm{b}+\mathrm{d})$ & 1 \\
\hline Total observado & & 1 & 1 & \\
\hline
\end{tabular}

As variáveis necessárias para a realização dos cálculos são:

$\mathrm{N}$ - Número total de observações. $\mathrm{N}=\mathrm{a}+\mathrm{b}+\mathrm{c}+\mathrm{d}$;

$\mathrm{G}$ - Número de acertos na previsão. $\mathrm{G}=\mathrm{a}+\mathrm{d}$;

$\mathrm{H}$ - Número esperado de acertos. $\mathrm{H}=\mathrm{N}$. $(1-\mathrm{p}) \cdot(1-\mathrm{q})+\mathrm{N} \cdot \mathrm{p} \cdot \mathrm{q}) ; \mathrm{p}=\mathrm{N} 1 / \mathrm{N}$ e q $=\mathrm{N} 2 / \mathrm{N}$;

$\mathrm{SS}$ - Skill score. $\mathrm{SS}=(\mathrm{G}-\mathrm{H}) /(\mathrm{N}-\mathrm{H})$;

$\mathrm{PS}$ - Porcentagem de sucesso. $\mathrm{PS}=\mathrm{G} / \mathrm{N}$.

\section{Apoio à tomada de decisão}

O sistema deverá informar ao usuário, em função do grau de perigo observado, as medidas preventivas que deverão ser tomadas, conforme descrito na tabela 6 .

\section{Modelagem de dados}

Especificação do Modelo Conceitual

$\mathrm{Na}$ especificação do Modelo Conceitual, foi desenvolvido o Diagrama de EntidadeRelacionamento, apresentado na figura 5. O modelo apresenta em sua estrutura a capacidade de armazenar dados meteorológicos, representados pela entidade Dados_Clima, de índices de perigo de incêndios florestais, representados pela entidade Índice_Perigo, além de dados sobre a ocorrência de incêndios florestais, representados pela entidade Ocorrência. Entidades auxiliares, como Dia_semana, Detecção, Causa, Tipo_incêndio, Vegetação, Combustível, Relevo, Tipo_combate e Local, foram utilizadas para modelar toda a estrutura de dados necessária. 
Tabela 6. Atividades Preventivas.

Table 6. Prevention Activities.

\begin{tabular}{|c|c|}
\hline Grau de perigo & Medidas preventivas \\
\hline Nulo & $\begin{array}{l}\text { Não existe perigo de incêndios. Deve-se usar esse período para iniciar o } \\
\text { treinamento de pessoal e planejamento das atividades. Inicia-se a manutenção de } \\
\text { aceiros, estradas, acesso aos pontos de captação de água e a revisão de todas as } \\
\text { ferramentas, equipamentos de proteção individual, demais equipamentos, veículos } \\
\text { e sistema de comunicação. A vigilância preventiva pode ser desmobilizada. As } \\
\text { torres não precisam operar. }\end{array}$ \\
\hline Pequeno & $\begin{array}{l}\text { O perigo de incêndios é pequeno. Deve-se usar esse período para intensificar o } \\
\text { treinamento de pessoal e planejamento das atividades. Intensifica-se a manutenção } \\
\text { de aceiros, estradas, acesso aos pontos de captação de água e a revisão de todas as } \\
\text { ferramentas, equipamentos de proteção individual, demais equipamentos, veículos } \\
\text { e sistema de comunicação. A vigilância preventiva pode ser reduzida. As torres não } \\
\text { precisam operar. }\end{array}$ \\
\hline Médio & $\begin{array}{l}\text { O perigo de incêndios é médio. Os meios de controle, como equipes de combate, } \\
\text { ferramentas, equipamentos de proteção individual, demais equipamentos, veículos } \\
\text { e sistema de comunicação devem estar em condições de serem usados. Os aceiros, } \\
\text { estradas e acesso a pontos de captação de água devem estar em boas condições. } \\
\text { Veículos e equipamentos de comunicação devem ser ligados e testados } \\
\text { diariamente. As torres começam a operar. }\end{array}$ \\
\hline Alto & $\begin{array}{l}\text { O perigo de incêndios é alto. Os meios de controle, como equipes de combate, } \\
\text { ferramentas, equipamentos de proteção individual, demais equipamentos e veículos } \\
\text { e sistema de comunicação devem estar em condições de serem usados A vigilância } \\
\text { preventiva deve ser intensificada, aumentando o período de operação das torres e } \\
\text { de vigilância móvel. A passagem por áreas críticas será limitada. As operações } \\
\text { agrícolas e florestais que usam fogo devem ser limitadas. Veículos e equipamentos } \\
\text { de comunicação devem ser ligados e testados pelo menos duas vezes ao dia. }\end{array}$ \\
\hline Muito Alto & $\begin{array}{l}\text { O perigo de incêndios é muito alto. Os meios de controle, como equipes de } \\
\text { combate, ferramentas, equipamentos de proteção individual, demais equipamentos } \\
\text { e veículos e sistema de comunicação devem estar em condições de serem usados A } \\
\text { vigilância preventiva deve ser intensificada, aumentando o período de operação das } \\
\text { torres e de vigilância móvel. A passagem por áreas críticas será muito limitada, não } \\
\text { se permitindo o uso do fogo nas proximidades dessas áreas. As operações agrícolas } \\
\text { e florestais que usam fogo devem ser suspensas. A população deve ser avisada por } \\
\text { veículos de comunicação, como rádio e televisão, para que tome medidas } \\
\text { preventivas. Equipes de primeiro combate devem ficar de plantão para qualquer } \\
\text { eventualidade. }\end{array}$ \\
\hline
\end{tabular}

Especificação do Modelo Lógico

Na especificação do Modelo Lógico, foi feita a descrição de todas as tabelas referentes aos dados meteorológicos e aos índices de perigo de incêndios, e das tabelas referentes à ocorrência de incêndios florestais. Para algumas tabelas auxiliares, foram definidas as opções para preenchimento dos campos, com o objetivo de padronizar as informações. Foram também definidas as operações desejadas sobre cada uma das tabelas, visando a manutenção do banco de dados e uma maior flexibilidade na interface com outros sistemas.

\section{Descrição das tabelas referentes aos dados meteorológicos e índices de perigo de incêndios florestais}

Dados_clima (data, local, altitude, umidade_relativa_13, precipitação_diária, velocidade_vento_13)

Operações: inclusão, alteração, exclusão, importação de dados, exportação de dados.

Índice_perigo (data, local, acumulado, PerigoFma, grau_perigo, valor_fmamais, PerigoFmamais)

Operações: valores calculados a partir da tabela de clima, exportação de dados. 
Restrição (lim_inferior, lim_superior, dedução)

Operações: inclusão, alteração, exclusão.

PerigoFma (código, val_inferior, val_superior, grau_perigo)

Operações: inclusão, alteração, exclusão.

PerigoFmamais (código, val_inferior, val_superior, grau_perigo)

Operações: inclusão, alteração, exclusão.

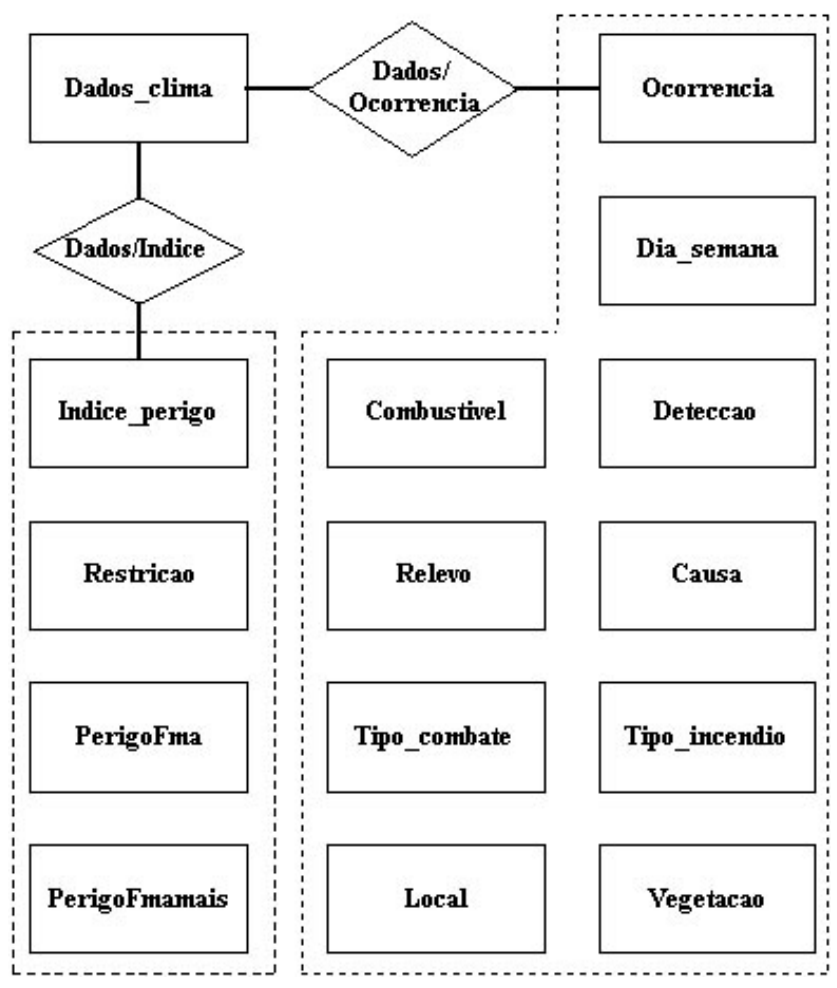

Figura 5. Diagrama de Entidade-Relacionamento.

Figure 5. Entity-Relationship Diagram.

\section{Descrição das tabelas referentes à ocorrência de incêndios florestais}

Ocorrência (data, local, dia_semana, latitude, longitude, hora_detecção, hora_incêndio_controlado, hora_incêndio_extinto, informante, área_queimada, detecção, causa, tipo_incêndio, vegetação, combustível, relevo, tipo_combate)

Operações: inclusão, alteração, exclusão, importação de dados, exportação de dados.

Dia_semana (código, dia)

Opções de Dia_semana: domingo, segunda-feira, terça-feira, quarta-feira, quinta-feira, sexta-feira, sábado.

Operações: inclusão, alteração, exclusão.

Detecção (código, forma detecção)

Opções de Detecção: vigilante móvel, vigilante fixo, vizinho, torre, avião, satélite, outros Operações: inclusão, alteração, exclusão.

Causa (código, causa)

Opções de Causa: raios, incendiários, queimas_para_limpeza, fumantes, recreação, estradas_de_ferro, operações florestais, diversos.

Operações: inclusão, alteração, exclusão. 
Tipo_incêndio (código, tipo_incêndio)

Opções de Tipo de Incêndio: subterrâneo, superficial, copa.

Operações: inclusão, alteração, exclusão.

Vegetação (código, tipo_vegetação)

Opções de Vegetação: nativa, exótica.

Operações: inclusão, alteração, exclusão.

Combustível (código, tipo_combustível)

Opções de Combustível: pasto, agricultura, capoeira, campo, floresta nativa, pinus, eucalipto, araucaria, outras florestas plantadas.

Operações: inclusão, alteração, exclusão.

Relevo (código, tipo_terreno)

Opções de Relevo: plano, ondulado, medianamente ondulado, fortemente ondulado.

Operações: inclusão, alteração, exclusão.

Tipo_combate (código, tipo_combate)

Opções de Tipo de Combate: ataque direto, ataque pelos flancos, contra-fogo, apoio aéreo, apoio terrestre.

Operações: inclusão, alteração, exclusão.

Local (código, local)

Operações: inclusão, alteração, exclusão.

É importante salientar que os detalhes internos de armazenamento não foram descritos no modelo lógico, pois essas informações fazem parte do modelo físico, que é a tradução do modelo lógico para a linguagem do software escolhido para implementar o sistema.

\section{RECOMENDAÇÕES GERAIS}

A partir das especificações funcionais e de dados desenvolvidas neste trabalho, recomenda-se:

- O sistema especificado deve ser desenvolvido utilizando qualquer linguagem de programação visual capaz de manipular uma base de dados relacional.

- A estrutura de dados apresentada é adequada a qualquer Sistema de Gerenciamento de Banco de Dados Relacional existente no mercado, o que possibilita a sua implementação em qualquer plataforma de software que apresente essa característica.

\section{REFERÊNCIAS}

BATISTA, A. C. Incêndios florestais. Recife: UFRPE, 115p. 1990.

CHENEY, N. P. Predicting fire behavior with fire danger tables. Australian Forestry, Queen Victoria, v. 32, n. 2, p. 71-79. 1968.

DATE, C. J. Introdução a sistemas de bancos de dados. Rio de Janeiro: Campus, 2000.

GANE, C.; SARSON, T. Análise estruturada de sistemas. 18.ed. Rio de Janeiro: Livros Técnicos e Científicos,. 1995.257p.

HEIKKILÄ, T. V.; GRONOVIST, R.; JURVÉLIUS, M. Handbook on forest fire control. Helsinki: [s.n.], 1993. 239p. (Forestry Training Programme Publication 21).

NUNES, J. R. S. FMA ${ }^{+}$- Um novo índice de perigo de incêndios florestais para o Estado do Paraná - Brasil. 150f. Tese (Doutorado em Engenharia Florestal) - Setor de Ciências Agrárias, Universidade Federal do Paraná, Curitiba, 2005.

POMPILHO, S. Análise essencial. guia prático de análise de sistemas. Rio de Janeiro: IBPI, 1995. 
SAMPAIO, O. B. Análise da eficiência de quatro índices na previsão de incêndios florestais para a região de Agudos - SP. 157f. Tese (Doutorado em Engenharia Florestal) - Setor de Ciências Agrárias, Universidade Federal do Paraná, Curitiba, 1999.

SCHROEDER, M. J.; BUCK, C. C. Fire weather. Madison: USDA Forest Service, 229p. 1970. (Agriculture Handbook, n. 360).

SILBERSCHATZ, A.; KORTH, H.; SUDARSHAN, S. Sistema de bancos de dados. 3.ed. São Paulo: Makron Books, 1999.

SOARES, R. V. Índices de perigo de incêndio. Revista Floresta, Curitiba, v. 3, n. 3, p. 19-40, 1972. 1972a.

SOARES, R. V. Determinação de um índice de perigo de incêndio para a região centro paranaense, Brasil. 72p. Dissertaçao (Mestrado) - Instituto Interamericano de Ciencias Agrícolas da OEA. Departamento de Ciencias Florestais/Centro Tropical de Ensino e Investigaçao, Turrialba, 1972. 1972 b.

SOARES, R. V. Prevenção e controle de incêndios florestais. [S.1.]: ABEAS, 120p. 1984.

SOARES, R. V. Incêndios Florestais: controle e uso do fogo. Curitiba, Fundação de Pesquisas Florestais do Paraná, 1985. 213p.

SOARES, R. V.; BATISTA, A. C. Meteorologia e climatologia florestal. Curitiba, 2004. 195p.

YOURDON, E. Análise estruturada moderna. Rio de Janeiro: Campus, 1992. 836p 